\title{
Panorama de la protección económica y asistencial pública y privada de las personas mayores en España
}

\author{
Framework of the Economic and Health Care Assistance \\ for Elderly People in Spain
}

\author{
Inés SÁNCHEZ-Ventura MORER \\ Profesora de Derecho Civil \\ Universidad de Navarra
}

Resumen: Actualmente, el sistema de asistencia social y sanitaria por un lado, y el sistema de pensiones por otro, se muestran claramente insuficientes para atender las necesidades que puedan tener los mayores una vez que acceden a la jubilación. Así lo demuestran los datos estadísticos que se aportan en la primera parte del trabajo. Si bien es cierto que muchas personas mayores son atendidas por sus familiares más cercanos, quienes asumen de forma natural el cuidado de sus ascendientes, resulta necesario desarrollar y fomentar la contratación de instrumentos jurídicos de carácter privado que den cobertura a las necesidades expuestas. Se trata de instrumentos que, a día de hoy, apenas representan un porcentaje significativo en el patrimonio de las personas mayores pero que buscan ser un complemento a la oferta pública de servicios. En todo caso, serán siempre complementarios y no sustitutivos de la oferta pública. De este modo si agentes públicos y privados actúan de manera conjunta, pueden llegar a ofrecer una protección completa a los problemas específicos de suficiencia económica, salud, vivienda, cultura y ocio a los que hace referencia el artículo 50 de la Constitución española. El presente trabajo pretende ofrecer una descripción básica de la situación en la que se encuentran los mayores y los instrumentos que de un lado y otro existen para dar cobertura a dichos problemas.

Palabras clave: mayores; jubilación; dependencia; conversión de activos inmobiliarios.

\begin{abstract}
Nowadays, the Spanish public health care system on the one hand, and the pension system on the other, are hardly enough to serve elderly needs once they retire. The statistical data that I use in the first part of this paper may show it. Although family care still remains the main way to provide care to elderly people -traditionally, it was taken for granted that the family would take care of family members in need of care- it is now required to develop other alternatives at the private sector to serve their needs. However, despite the increasing interest in alternative investments, these kind of assets hardly represent a significant proportion in elderly budgets. At the same time we have to take into account that these instruments are designed to complement the public resources, not to replace them. Nevertheless, if private and public institutions work together it would be possible to provide a complete protection for their specific problems of adequate income, health, housing, culture and leisure, needs that the Spanish constitution refers to in its section 50. This paper intends to offer a brief description about the status of the elderly in our society and the solutions the public network and private market can offer them
\end{abstract}

Keywords: elderly; retirement; long-term care; equity release schemes.

\section{Planteamiento de la CUeStión}

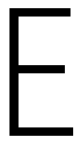

1 punto número 9 del preámbulo de la Decisión no 940/2011/UE del Parlamento y el Consejo de 14 de septiembre de 2011 sobre el Año Europeo del Envejecimiento Activo y de la Solidaridad Intergeneracional (2012) señalaba: «el envejecimiento activo permite que las personas realicen su 
potencial de bienestar fisico, social y mental a lo largo de toda su vida y que participen en la sociedad, a la vez que se les proporciona una protección, una seguridad y unos cuidados adecuados cuando lo necesiten. De abi que el fomento del envejecimiento activo exija un enfoque multidimensional, así como responsabilización y apoyo permanente entre todas las generaciones».

Precisamente apoyada en este enfoque multidimensional que exige la atención de las personas mayores voy a tratar aquí de algunas de las posibilidades que ofrecen el Derecho Público y el Derecho Privado para el cuidado de la persona mayor. En concreto, trataré de determinar qué papel cumple el Derecho patrimonial en la atención privada de las personas mayores, en una materia caracterizada por un continuo ir y venir del Derecho público al Derecho privado que, lejos de contraponerse, están llamados a complementarse de cara a lograr un sistema eficaz de atención a los mayores. Este estudio no pretende atender únicamente al lado subjetivo de la relación de cuidados; es decir, quién se hace cargo de la atención sino, fundamentalmente, cómo se financian los mismos.

Las posibilidades que ofrece el ordenamiento jurídico son distintas en función de la situación en la que se encuentre el mayor. Para valorar cuál es la solución que resulta más adecuada al caso concreto tres son los factores que hay que tener en cuenta y que influyen en la calidad de vida de los mayores: su estado de salud, su situación familiar y su situación económica.

Según cuáles sean las condiciones de vida en relación a estos tres factores, los recursos que el Derecho público y el Derecho privado ponen a disposición de este colectivo de la población son muy variados; sin embargo, podemos distinguir a tres grandes grupos de recursos:

En primer lugar, prestaciones públicas que reconoce el Estado. A su vez, en este primer grupo deberíamos distinguir dos tipos de prestaciones públicas, siguiendo el enunciado del art. $50 \mathrm{CE}$ : las pensiones y aquellas que proveen cobertura sanitaria y asistencial.

En segundo lugar, formas de convivencia y situación familiar. En este apartado podremos medie el nivel de atención prestada en el entorno familiar. No en vano España responde a un sistema de cuidados informales de carácter mediterráneo que descansa fundamentalmente en la familia.

Por último, la inversión de recursos propios. En este tercer grupo destacamos: los instrumentos de previsión o ahorro que pretenden atender a una futura contingencia, y otros recursos de carácter privado que, por el contrario atienden las situaciones de falta de liquidez una vez que estas se producen.

Ninguna de las tres fuentes de recursos tiene carácter exclusivo y excluyente, sino que como ya anunciaba anteriormente están llamadas a comple- 
mentarse; lo que resulta de lo más conveniente si efectivamente se quiere dar una respuesta adecuada a la atención de los mayores.

Comenzaremos por caracterizar las condiciones de vida de los mayores.

\section{Estado de Salud}

Las personas mayores cada vez viven más, la media de esperanza de vida se sitúa en los 85 años para las mujeres y 80 años para los hombres ${ }^{1}$. Sin embargo, esta mayor esperanza de vida no siempre va acompañada de buena salud ya que el avance de los años lleva consigo el deterioro físico de las personas y la aparición de numerosas limitaciones. Es más, «los mayores suponen el 42,5\% de todas las altas hospitalarias y presentan estancias más largas que el resto de la población $»^{2}$, siendo los principales usuarios del sistema hospitalario.

En la última encuesta nacional de salud realizada en el año 2012 por el Ministerio de Sanidad, un 75\% aproximadamente de la población mayor de 85 años declara poseer problemas de movilidad, dolor y malestar; así como dificultades para realizar actividades de la vida diaria. Estos porcentajes se reducen a un $50 \%$ de media en el caso de personas entre 75 y 84 años y a un 30\% en el caso de personas de entre 65 y 74 años ${ }^{3}$. Muchos de los problemas declarados por los mayores no se asocian a una enfermedad concreta sino al propio devenir de la vida, generándose esas dificultades de movilidad y realización de actividades de la vida diaria que se asocian con situaciones de dependencia que requieren, no la asistencia puntual que ofrece de por sí el sistema hospitalario sino, cuidados de larga duración y, por lo tanto, la prestación de asistencia específica por parte de un tercero. Desde el año 2006 el legislador ha querido dar respuesta al fenómeno de la dependencia mediante el reconocimiento de prestaciones que diesen cobertura a este fenómeno. La Ley 39/2006 de 14 diciembre de Promoción para la Autonomía Personal y Atención a las personas en situación de Dependencia desarrollaba un sistema con cargo a los presupuestos del Estado, de carácter eminentemente asistencial, en el que los

1 A. Abellán García y R. Pujol Rodríguez, «Un perfil de las personas mayores en España, 2015. Indicadores estadísticos básicos», Informes Envejecimiento en red $n^{\circ} 10$, Madrid, 2015, disponible en: <http://envejecimiento.csic.es/documentos/documentos/enred-indicadoresbasicos15.pdf> [Fecha de publicación: 22/01/2015], p. 3.

2 Ibid., p. 12.

3 Ministerio de Sanidad, Servicios Sociales e Igualdad e INE, Encuesta Nacional de Salud 20112012, disponible en: <http://www.msssi.gob.es/estadEstudios/estadisticas/encuestaNacional/ encuesta2011.htm> [Fecha de consulta: 24/02/2016], p. 22. 
beneficiarios iban a participar sufragando parte del gasto del servicio de acuerdo con su nivel económico.

Puede resultar ilustrativo añadir a las estadísticas anteriores, los datos relativos a personas mayores en situación de dependencia ya que a través del sistema de autonomía y atención a la dependencia se pretende atender a los problemas de salud declarados por los mayores y recogidos en el párrafo anterior. Si bien es cierto que la dependencia no es un fenómeno asociado al envejecimiento, una vez más resulta que los principales beneficiarios son las personas mayores de 65 años. Si atendemos al perfil de solicitantes de prestación por dependencia a 31 de diciembre de 2015 , resulta que vienen a representar un $83 \%$ de los solicitantes (1.221.631 del total que asciende a $1.610 .714)^{4}$.

Otro fenómeno que vuelve a presentarse de manera acusada entre los mayores es el de la discapacidad ${ }^{5}$. El número de personas mayores que tienen reconocido un grado de discapacidad ${ }^{6}$ superior al $33 \%$ es de 1.195 .352$.

\section{Formas de convivencia y situación familiar}

En este apartado pretendemos determinar dónde y cómo viven los mayores y la relación con sus familiares quienes, con carácter general, independientemente de las posibles ayudas que reciban del Estado, son los principales cuidadores de las personas mayores.

4 Ministerio de Sanidad, Servicios Sociales e Igualdad, IMSERSO, Portal de la dependencia, Estadística mensual: perfil de la persona solicitante: sexo y edad. Datos de la gestión a 31 de diciembre de 2015, disponible en: <http://www.dependencia.imserso.gob.es/dependencia_01/documentacion/estadisticas/ est_inf/datos_estadisticos_saad/index.htm> [Fecha de consulta 25/02/16].

5 Discapacidad y dependencia responden a dos realidades diferentes aunque están relacionadas entre sí ya que la discapacidad puede llevar consigo la necesidad de asistencia de un tercero. Sólo cuando necesite del concurso de una tercera persona podremos hablar de sujeto dependiente. En este sentido el art. 2.2 de la Ley 39/2006 recoge la discapacidad como una de las causas de la dependencia: «estado de carácter permanente en que se encuentran las personas que, por razones derivadas de la edad, la enfermedad o la discapacidad, y ligadas a la falta o a la pérdida de autonomía fisica, mental, intelectual o sensorial, precisan de la atención de otra u otras personas o ayudas importantes para realizar actividades básicas de la vida diaria o, en el caso de las personas con discapacidad intelectual o enfermedad mental, de otros apoyos para su autonomía personal».

6 Ministerio de Sanidad, Servicios Sociales e Igualdad, Secretaria de Estado de Servicios Sociales e igualdad, IMSERSO, Base estatal de datos de valoración del grado de discapacidad: informe a 31/12/2014, disponible en: <http://imserso.es/InterPresent1/groups/imserso/documents/binario/bdepcd_2014.pdf> [Fecha de consulta: 25/02/16], p. 17. 
La forma de convivencia ${ }^{7}$ más común entre los mayores es en pareja y sin hijos en su propio domicilio, representan un $40 \%$ de los hogares de la población de 65 años o más, seguido de las personas que viven solas (también en su domicilio) que representan un 22,5\%. A la pregunta de dónde prefieren vivir los mayores, un $85 \%$ de media señala que en su propia casa y la segunda opción más valorada es en casa de sus familiares ${ }^{8}$. Por otro lado, estos datos también se corresponden con el régimen general de tenencia de la vivienda, bien es sabido que España se caracteriza por tener uno de los índices más altos de régimen de vivienda en propiedad (89\%) frente al régimen de alquiler'.

Lo cierto es que las personas que viven en centros residenciales apenas representan un porcentaje significativo dentro del conjunto de la población mayor de 65 años. Actualmente estos centros cuentan con 381.480 plazas distribuidas en 6.610 centros y se encuentran con un índice de ocupación del 64\%. Deberíamos añadir además que tan sólo el $47 \%$ es de financiación pública ${ }^{10}$. Estos datos vienen a confirmar que la mayor parte de la población reside en su propio hogar y como veremos más adelante cuidados por sus familiares más cercanos, y es que el sistema de servicios sociales no está tan extendido como a primera vista pudiera parecer. Así, la familia sigue teniendo una impronta fundamental para las personas mayores no sólo porque sean sus principales cuidadores sino porque la mayor parte del tiempo transcurre junto con sus familiares ${ }^{11}$.

7 Instituto Nacional de Estadística, Las formas de convivencia: $20^{\circ}$ aniversario del Año Internacional de la Familia, Boletín informativo del Instituto Nacional de Estadística, julio 2014, disponible en: <http://www.ine.es/ss/Satellite?c=Page\&cid=1254735116567\&pagename=ProductosYServi cios\%2FPYSLa yout\&L=es_ES> [Fecha consulta: 20/02/2016], p. 7.

8 Ministerio de Sanidad, Servicios Sociales e Igualdad, Secretaria de Estado de Servicios Sociales e igualdad, IMSERSO, Informe 2012. Las Personas Mayores en España: datos Estadísticos Estatales y por Comunidades Autónomas, Colección Documentos, Serie Documentos Estadísticos, nº 22027, disponible en el catálogo de publicaciones de la Administración General del Estado: http:// publicacionesoficiales.boe.es/ [Fecha de consulta 26/02/16], 189.

9 INE, Encuesta de condiciones de vida: resultados definitivos. Disponible en: <http://www.ine. es/dyngs/INEbase/es/operacion.htm?c=Estadistica_C\&cid $=1254736176807 \&$ menu=ulti Datos\&idp=1254735976608> [Fecha de publicación: 26/05/2015].

10 Ministerio de Sanidad, Servicios Sociales e Igualdad, Secretaria de Estado de Servicios Sociales e igualdad, IMSERSO, Informe 2014. Las Personas Mayores en España: datos Estadísticos Estatales y por Comunidades Autónomas, Colección Documentos, Serie Documentos Estadísticos, n 22027 , disponible en el catálogo de publicaciones de la Administración General del Estado: http:// publicacionesoficiales.boe.es/ [Fecha de consulta 26/02/16], pp. 180 y 181 y tabla p. 214.

11 Ministerio de Sanidad, Informe 2012, op. cit., p. 193. 
Los hogares unipersonales están formados principalmente por mujeres ${ }^{12}$ viudas. En este punto resulta interesante la relación existente, tal y como han destacado algunos estudios, entre las formas de convivencia de los mayores y su capacidad económica; de tal manera que la diferencia es notable entre la renta mediana de los mayores que viven solos, que en ocasiones no llega a alcanzar los dos tercios de la media nacional, y los que viven en pareja (un $95 \%$ de las personas mayores poseen una renta mediana que se corresponde con el promedio nacional) ${ }^{13}$. Esta situación se ajusta a la realidad teniendo en cuenta que la mayor parte de los hogares unipersonales son ocupados por mujeres que cobran fundamentalmente la pensión de viudedad como se verá más adelante.

Ya que nos hemos introducido en el ámbito económico trasladémonos ahora al tercero de los factores que íbamos a analizar: capacidad económica de los mayores.

\section{Situación económica}

A la hora de valorar la situación económica de los mayores se ha tener en cuenta, fundamentalmente dos factores: nivel y fuente de ingresos y tasa de pobreza entre los mayores.

Aunque más adelante se hablará de los activos patrimoniales de los que disponen los mayores, la principal fuente de ingresos de los mayores se corresponde con la pensión del régimen general (jubilación o viudedad en su caso). El nivel de renta de los mayores españoles se sitúa en torno a los $13.500 €$ aproximadamente ${ }^{14}$, lo que se identifica con el importe de la pensión que a uno de enero de 2016 alcanza los $1.312 €$ mensuales de media en el caso de hombres y de $896 €$ de media en el caso de las mujeres. Si comparamos España con el resto de los países europeos, España suele ocupar una posición medio-baja, ni representa el país con mayor nivel de renta pero tampoco es de los de menor renta. Además de la diferencia que puede existir entre hombres y mujeres hay que tener en cuenta la edad, ya que el nivel de ingresos disminuye conforme avanza la edad en una relación inversamente proporcional ${ }^{15}$.

12 INE, Las formas de convivencia: $20^{\circ}$ aniversario del Año Internacional de la Familia, op. cit., p. 6.

13 Ministerio de Sanidad, Informe 2012, op. cit., pp. 74 y 75.

14 Ministerio de Sanidad, Informe 2014, op. cit., p. 79.

15 Ibid., p. 80. 
Aunque las pensiones no garanticen el mismo nivel de ingresos que se alcanzaba con anterioridad a la jubilación y aunque no parezcan suficientes para garantizar un nivel alto de bienestar la tasa de pobreza ${ }^{16}$ no es precisamente elevada; si bien es cierto que en el caso de los hombres es algo inferior al de las mujeres, un $11,4 \%$ y un $12,5 \%$ respetivamente. Todo ello a pesar de que un $11 \%$ de los mayores de 65 años declara tener unos ingresos ${ }^{17}$ entre 301 y $600 €$, un $25 \%$ entre 601 y $900 €$ y un $13 \%$ entre 900 y $1200 €$. Estas cantidades pueden resultar claramente insuficientes si atendemos a una estructura de gasto común de una familia de edad media; sin embargo, la estructura de gasto varía algo entre las personas mayores. El gasto fundamental es el mantenimiento de la propia vivienda, seguido del gasto en alimentación, ocio, hoteles y restauración... Un lector observador habrá advertido que no aparecen reflejados los costes relacionados con la salud o la atención de cuidados de larga duración, estos apenas representan un $3 \%$ del tota ${ }^{18}$ lo cual puede venir motivado por dos razones principales: bien porque son cubiertas por el Estado, bien porque, como ocurre en la mayoría de las ocasiones, son cubiertos por sus familiares de una manera indirecta.

Del análisis de las condiciones de vida de los mayores en relación a su salud y a su situación económica, concluimos que nos encontramos con una población mayor de ingresos ajustados, reducidos a la pensión de jubilación, que no permite al mayor realizar desembolsos importantes en caso de necesitar ayuda de un tercero. La cuestión que se plantea entonces es cómo cubrir esa necesidad. A esta pregunta debemos dar respuesta analizando los distintos recursos enunciados anteriormente con los que cuenta o puede llegar a contar el mayor.

\section{PRestaciones PÚblicas y SERVICIOS SOCIALES}

Suponen la respuesta que, desde el ámbito público, se da a este conjunto de necesidades. La protección constitucional de la tercera edad se encuentra recogida en el art. $50 \mathrm{CE}$ : «Los poderes públicos garantizarán, mediante pensiones adecuadas y periódicamente actualizadas, la suficiencia económica a los ciudadanos

\footnotetext{
16 Para medir la tasa de pobreza se tienen en cuenta dos indicadores: nivel de ingresos medios y el nivel de carencia material. Vid., INE, Encuesta de condiciones de vida: resultados definitivos, op. cit., pp. 111 y 112.

17 Ministerio de Sanidad, Informe 2014, op. cit., p. 242.

18 A. Abellán GarCía, «Un perfil de las personas mayores en España...», op. cit., p. 18.
} 
durante la tercera edad. Asimismo, y con independencia de las obligaciones familiares, promoverán su bienestar mediante un sistema de servicios sociales que atenderán sus problemas específicos de salud, vivienda, cultura y ocio».

Este artículo forma parte del Capítulo III de la Constitución española que recoge los principios rectores de la política social y económica. Estos principios como tales hacen referencia al conjunto de los derechos económicos, sociales y culturales más conocidos como «derechos de tercera generación», incorporados a nuestro ordenamiento jurídico en el año 1978. Tras un proceso de larga duración en el reconocimiento de derechos, España se constituye, tal y como señala el art. $1 \mathrm{CE}$, en un Estado social y democrático de Derecho.

El reconocimiento de estos derechos de tercera generación conlleva una serie de implicaciones que deben ser tenidas en cuenta a la hora de interpretar el conjunto de artículos recogidos en el capítulo III. En primer lugar «se trata de derechos de prestación cuya efectividad requiere la creación, organización y sostenimiento financiero de un servicio público. De ello se deriva una consecuencia capital: su eficacia ya no depende, tan sólo, de la voluntad política y de la articulación jurídica sino, además, de la posibilidad económica de crear y financiar el servicio y de la determinación de las fuentes financieras y de las prioridades del gasto público, que son funciones de naturaleza esencialmente política» ${ }^{19}$.

En segundo lugar, recogen derechos que si bien no cuentan con la máxima protección que puede otorgar la Constitución a través del recurso de amparo, hacen referencia a principios cuya finalidad principal es la de dirigir y coordinar la acción de los poderes públicos, son principios que no vinculan directamente pero tienen un enorme valor interpretativo ${ }^{20}$.

Descendiendo ya al art. $50 \mathrm{CE}$ en este artículo el legislador hace referencia a dos mecanismos de protección de las personas mayores: la suficiencia económica y la cobertura sanitaria y asistencial. Pero, en la línea de lo que se ha afirmado en los párrafos anteriores, dependiendo de la buena o mala organización de los recursos públicos, será necesario buscar otras soluciones en el ámbito privado. Es decir, en función de hasta dónde se extienda la cobertura

19 A. FernÁNDEZ-Miranda CAMPOAMOR, «El Estado social», Revista española de derecho constitucional, Año no 23, nº 69 (2003), p. 158

20 F. Balaguer Callejón (coord.), G. Cámara Villar et al., Manual de Derecho constitucional, vol. II, Tecnos, Madrid, 2005, p. 49; y A. FernándeZ-Miranda CAMPOAMOR, «El Estado social», op. cit., pp. 158 a 160. 
que ofrece la Seguridad Social y otros servicios sociales de carácter local, el mayor se verá más o menos libre de destinar recursos complementarios a financiar sus cuidados.

Trataremos ahora cada uno de los ámbitos regulados en el art. $50 \mathrm{CE}$ por separado.

\section{Pensiones}

El primer inciso del art. $50 \mathrm{CE}$ determina que: Los poderes públicos garantizarán, mediante pensiones adecuadas y periódicamente actualizadas, la suficiencia económica a los ciudadanos durante la tercera edad... Los términos: pensión adecuada y suficiencia económica recogidos en este artículo, hay que interpretarlos a la luz de la configuración de nuestro sistema de pensiones, basado en el principio de solidaridad intergeneracional, de carácter contributivo, obligatorio y de reparto, lo que supone que «las prestaciones anuales que están cobrando los pensionistas se financian mediante las cotizaciones que en ese mismo año realizan las empresas y los trabajadores en activo $\gg^{21}$. Por lo tanto, pensión adecuada no es aquella que está determinada por el historial asegurador del pensionista sino que debe entenderse desde la óptica del sistema de pensiones en su conjunto, sin considerar cada retribución de forma individual. Por otro lado, «el mandato de suficiencia económica de las pensiones de la tercera edad contenido en el art. 50 nos sitúa ante una intensidad protectora mínima, desempeñando una función de garantía de ingresos mínimos existenciales ${ }^{22}$. Esto se debe a que el Estado lo que realmente puede hacer es repartir los recursos limitados de los que dispone de forma equilibrada, teniendo en cuenta las circunstancias socio-económicas, entre todos sus pensionistas ${ }^{23}$.

Estas circunstancias socio-económicas han cambiado bastante a lo largo de los últimos años. El descenso de la natalidad ha llevado consigo la disminución de la población activa lo que supone que «el ratio de trabajador en activo por cada pensionista... va a bajar de forma sustancial» ${ }^{24}$. Algún estudio

21 Por un sistema de pensiones sostenible e inteligente, Pricewaterhousecoopers, 2010, disponible en: $<$ http://www.pwc.com/es_ES/es/crecimientointeligente/assets/pensiones-sostenible-inteligente.pdf> [fecha de consulta 9/11/2010], p. 7.

22 J-L. Goñi Sein, «Comentario al art. 50», en E. Casas BaAmonde y M. Rodríguez-PiÑeRO, Comentarios a la Constitución Española en su XXX aniversario, Woters Kluver, Madrid, 2008, p. 1128.

23 F. Balaguer Callejón, Manual de Derecho constitucional, vol. II, op. cit., p. 257.

24 Por un sistema de pensiones sostenible e inteligente, op. cit., p. 12. 
ha llegado a señalar que la tasa de fecundidad debería ascender a seis hijos por mujer si se quiere garantizar el reemplazo ${ }^{25}$. Esta disminución en la población activa tiene su reflejo directo en la financiación de un sistema que ingresará cada vez menos y tendrá un gasto mayor ${ }^{26}$. También influyen en la suficiencia financiera del sistema, algunos cambios en la mentalidad socio-laboral que no pueden pasar inadvertidos. Me refiero a la tardanza en el acceso al primer empleo de los más jóvenes, y a la finalización cada vez más temprana de la etapa laboral en los mayores a través de la prejubilación y de la jubilación parcial ${ }^{27}$. Ambas situaciones reducen la población en activo ya que, o directamente no cotizan, o cotizan menos en el caso de la jubilación parcial.

Tal y como está configurado nuestro sistema de pensiones, caracterizado por la falta de correspondencia entre el salario obtenido y la cuantía de la pensión, no puede garantizarse a los mayores el mismo nivel de bienestar que se poseía con anterioridad a la jubilación, de tal manera que el sistema de pensiones requiere del complemento asistencial y sanitario dependiente fundamentalmente de la Seguridad Social y de los Servicios sociales en su mayoría gestionados por las Comunidades Autónomas.

\section{Cobertura sanitaria y asistencial}

El segundo gran ámbito de protección de las personas mayores, hace referencia a la cobertura sanitaria y asistencial, que aunque englobados bajo el mismo apartado hacen referencia a dos realidades distintas de extensión y ámbito de aplicación diferente, ya que mientras el sistema sanitario en España se caracteriza por su carácter universal -su protección alcanza a todos los ciudadanos-, el sistema de servicios sociales, por el contrario, es un sistema de prestación condicionada al cumplimiento de determinados requisitos como la no superación de determinado umbral de ingresos. El art. $50 \mathrm{CE}$ se dirige a los poderes públicos señalando que: «... Asimismo, y con independencia de las obligaciones familiares, promoverán (los poderes públicos) su bienestar mediante un sistema de servicios sociales que atenderán sus problemas específicos de salud, vivienda, cultura y ocio».

25 O. Peláez Herreros, «El gasto en pensiones contributivas en España 2007-2050», Principios: Estudios de Economía Política (on line), $\mathrm{n}^{\circ}$ 12, Fundación Sistema, 2008, p. 55.

26 Por un sistema de pensiones sostenible e inteligente, op. cit., p. 9.

27 Ibid., p. 11. 
Desde el punto sanitario, en nuestro país se ofrece ${ }^{28}$ una protección adecuada en lo que se refiere a diagnósticos, intervención quirúrgica, hospitalización, dispensación de medicamentos y tratamientos. Muy pocas contingencias están excluidas del sistema de la Seguridad Social. El problema radica en que, una vez transcurrido el proceso agudo se procede a dar el alta a la persona mayor que volverá a su residencia habitual con dificultades para llevar a cabo las actividades de la vida diaria.

En este punto, la necesidad de asistencia podría cubrirse con el segundo de los mecanismos recogidos en el art. $50 \mathrm{CE}$ a través de los servicios sociales gestionados por el IMSERSO, entre los cuales pueden destacarse: residencias, centros de día, teleasistencia y servicio de atención domiciliaria principalmente. Cada uno de estos servicios puede atender a la necesidad de cuidado por un tercero cuando la persona mayor encuentra dificultades para llevar a cabo las actividades diarias, es decir, cuando la persona mayor se encuentra en una situación de dependencia. Pero, tal y como se ha señalado más arriba, su campo de actuación se limita a quienes acreditan falta de apoyo social o familiar o bien un nivel de renta mínimo. Así, un gran porcentaje de mayores quedan fuera de esta protección y son atendidos por sus familiares. Como se dirá más adelante, el porcentaje de usuarios mayores de 65 años de los servicios sociales es más bien bajo.

En la introducción se hizo referencia a como el legislador, para cubrir la necesidad de atención y cuidados por parte de un tercero que se puede plantear durante la vejez, dictó la Ley 39/2006 de 14 de diciembre de Promoción para la Autonomía Personal y Atención a las personas en situación de dependencia (de ahora en adelante LADP). Se dice que la creación del sistema de atención a la dependencia venía a constituir el cuarto pilar del Estado de Bienestar $^{29}$. El art. 3 de la LADP recogía los principios que iban a regir el sistema:

28 A día de hoy, la protección de la salud de los mayores descansa fundamentalmente en la Seguridad Social a través del conjunto de complejos hospitalarios y centros de salud distribuidos a lo largo del país. Desde finales de los años ochenta, hasta prácticamente el año 2002, se ha ido produciendo la descentralización progresiva de la gestión de los servicios sanitarios. El antiguo Instituto Nacional de Salud fue sustituido por los correspondientes Servicios de Salud de cada una de las Comunidades Autónomas quedando bajo control estatal únicamente los servicios sanitarios de Ceuta y Melilla. Vid., I. SánCHEZ-Ventura Morer, La hipoteca Inversa en Derecho español, Thomson-Reuters, Civitas, Cizur Menor, 2013, pp. 34 y ss.

29 A. MONTERo SOLER «La atención a la dependencia en España: razones para una reforma ineludible», en R. CALVO ORTEGA (dir.), Situaciones de dependencia: regulación actual y nuevas perspectivas, Thomson-Civitas, Cizur Menor, 2007, p. 86. 
carácter público, universalidad e igualdad en el acceso de las prestaciones. Al mismo tiempo se preveía la creación de todo un conjunto de servicios sociales y la prestación económica vinculada al cuidado informal que tenía carácter supletorio.

Sin embargo, la LADP no ha satisfecho la finalidad para la cual había sido elaborada. Se decía que la LADP iba a garantizar una protección integral de las personas en esta situación; pero, y en la práctica, en lo que se refiere a la aplicación de la Ley de Dependencia, la falta de previsión presupuestaria de las Comunidades Autónomas (lo que ha sido denunciado continuamente por la prensa), y el número de solicitudes, claramente superior a lo inicialmente esperado, no ha llevado consigo la creación de nuevos servicios sino la asunción de los que ya existían, muchos de los cuales formaban parte de la oferta a los mayores ${ }^{30}$.

A ello se suma la decisión de aplicar gradualmente la ley, para lo que se diseñó un calendario de aplicación en virtud del cual se comenzarían a reconocer las situaciones de dependencia más graves o severas. De tal manera que, hasta el año 2013, no se empezaron a valorar y reconocer las situaciones de dependencia de nivel leve. Finalmente no ha sido hasta 2015 cuando han comenzado a reconocerse los casos de dependencia leve ${ }^{31}$.

En tercer lugar, si uno atiende a las cifras de solicitantes de la prestación y beneficiarios nos encontramos con que a 31 de diciembre de 2015 el número de beneficiarios con prestación es de 796.109 que si lo comparamos con el número de personas mayores de 65 años que ascendía en julio de 2015 a 8.600 .000 personas no viene a representar un porcentaje muy significativo ${ }^{32}$.

$\mathrm{Al}$ mismo tiempo, una de las características del sistema de atención a la Dependencia es la instauración del sistema copago, que supone la colaboración del usuario en el coste del servicio de acuerdo con su nivel económico y patrimonial ${ }^{33}$. En este sentido, puede decirse que la financiación de los servicios no es enteramente pública sino también privada. Es más, la propia LADP

30 Así se descubre cuando se consultan los diversos servicios que se ofertan a los mayores en el Catálogo de servicios disponible en la página web del IMSERSO tanto para mayores como para personas en situación de dependencia.

31 Ministerio de Sanidad, Servicios Sociales e Igualdad, IMSERSO, Portal de la dependencia, Avance de la Evaluación 2015 del Sistema para la Autonomía y Atención a la Dependencia, disponible en: <http://www.dependencia.imserso.gob.es/dependencia_01/evo_doc/e/eva_2015/index. htm> [Fecha de consulta 25/02/16], p. 7.

32 Datos demográficos disponibles en la página web oficial del Instituto Nacional de Estadística.

33 Art. 33 Ley de dependencia: «Los beneficiarios de las prestaciones de dependencia participarán en la financiación de las mismas, según el tipo y coste del servicio y su capacidad económica personal». 
preveía el desarrollo posterior de instrumentos jurídico-privados que diesen cobertura al fenómeno de la dependencia. En este sentido la disposición adicional séptima de la Ley de dependencia señalaba: «1. El Gobierno, en el plazo de seis meses, promoverá las modificaciones legislativas que procedan, para regular la cobertura privada de las situaciones de dependencia. 2. Con el fin de facilitar la cofinanciación por los beneficiarios de los servicios que se establecen en la presente Ley, se promoverá la regulación del tratamiento fiscal de los instrumentos privados de cobertura de la dependencia». De esta manera se busca que iniciativa privada e iniciativa pública se complementen para dar una respuesta más completa al fenómeno del envejecimiento y de la dependencia a él asociado.

\section{LA FAMILIA COMO CUIDADOR INFORMAL}

Y LA OBLIGACIÓN LEGAL DE ALIMENTOS

Cuando los padres empiezan a tener edades avanzadas, el porcentaje de personas que tienen a su padre, madre o a ambos conviviendo con ellos crece alcanzando niveles bastante elevados ${ }^{34}$. La red de solidaridad familiar funciona cuando las pensiones no son suficientes para garantizar la autonomía de los individuos y cuando, a causa del deterioro de su estado de salud, los ascendientes ancianos devienen personas dependientes ${ }^{35}$. Por otro lado, las prestaciones públicas no llegan a todos los ciudadanos, ni atienden todas las situaciones, ni de por sí son suficientes para cubrir una necesidad concreta $^{36}$.

$\mathrm{En}^{37} 2008$, el $86 \%$ de la población en situación de dependencia era atendida por sus familiares ${ }^{38}$. Si además realizamos a los mayores la pregunta sobre quién querría que le atendiese en el caso de necesitar cuidados, la respuesta sería que la mayor parte prefiere recibir cuidados de sus familiares ${ }^{39}$. Tanto es así que, de las 8.442 .427 personas mayores de 65 años que vivían en nuestro país el 31 de diciembre de 2013, tan sólo un $15 \%$ de la población es usuario

34 Libro Blanco «Atención a las personas en situación de dependencia en España», Ministerio de Trabajo y Asuntos Sociales, diciembre de 2004, p. 185.

35 Ibid., pp. 169 y 170.

36 N. Martínez RodrígueZ, «La obligación legal de alimentos entre parientes», La Ley (on line) (2002), p. 37.

37 La práctica totalidad de los estudios se basan en los datos de la Encuesta de Discapacidad, Autonomía Personal y Situaciones de Dependencia (EDAD) del 2008 elaborada por el INE, no se tienen datos más actualizados.

38 Ministerio de Sanidad, Informe 2014, op. cit., p. 323.

39 Ministerio de Sanidad, Informe 2012, op. cit., p. 190. 
de alguno de los siguientes servicios sociales: tele-asistencia, ayuda a domicilio, centros de día y centros residenciales ${ }^{40}$. Todos estos datos son reflejo del sistema de cuidados mediterráneo tan propio de nuestro país que se asienta fundamentalmente en el apoyo que presta la familia ${ }^{41}$.

Ahora bien, la incorporación de la mujer al mercado laboral, la desaparición de la familia extensa y la movilidad geográfica de sus miembros hace inviable en muchas ocasiones que la familia pueda hacerse cargo personalmente del cuidado de sus mayores. En un alto porcentaje, no están capacitados para ofrecer los cuidados profesionales, tantas veces necesarios, y se ven superados por la situación. Son contadas las ocasiones; sin embargo, en las que los familiares se abstienen de forma voluntaria de prestar esa ayuda. Pero en todos estos casos, los mayores y sus familiares cuentan con toda una red de recursos -de servicios sociales y prestaciones económicas- que poseen todas las Comunidades Autónomas cuyo objetivo principal es paliar las situaciones de necesidad en las que puedan encontrarse los mayores. Y pueden acudir a estos recursos incluso cuando existan familiares que al menos, desde el punto de visto económico, podrían mantenerles. No en vano el art. $50 \mathrm{CE}$ se dirige a los poderes públicos señalando su deber de promover un sistema de servicios sociales con independencia de las obligaciones familiares.

Son obligaciones que, desde el punto de vista del Derecho civil, encuentran su plasmación legal en la obligación de alimentos recogida en los artículos 142 y siguientes del Código Civil. Así según el art. 143 CC están obligados: los cónyuges y los ascendientes y descendientes entre $\mathrm{si}^{42}$. A su vez por alimentos se entiende, de acuerdo con el art. 142 CC, «todo lo que es indispensable para el sustento, habitación, vestido y asistencia médica». Ahora bien, cuando un hijo decide apoyar económica o asistencialmente a su padre o madre ya sea en el propio domicilio, ya sea en otro, no lo hace porque exista una obligación legal de alimentos recogida en el Código Civil sino porque su conciencia así se lo impone $^{43}$. Podría decirse que el deber de prestarse alimentos va más allá del carácter imperativo del art. 142 CC. En este sentido, la STS de 13 de abril de 1991 señala en su fundamento jurídico segundo que: «ha de tenerse en cuenta que la obligación alimenticia, se ha de entender como deber impuesto a una

\footnotetext{
40 Ministerio de Sanidad, Informe 2014, op. cit., p. 183.

41 Libro Blanco, op. cit., p. 169.

$42 \mathrm{El}$ art. $143 \mathrm{CC}$ también recoge el hecho de que los hermanos sólo se deben los auxilios entre sí.

43 N. MARTíneZ RodrígueZ, «La obligación legal de alimentos entre parientes», op. cit., p. 33.
} 
o varias personas, de asegurar la subsistencia de otra o de otras y supone la conjunción de dos partes, una acreedora, que tiene derecho a exigir y recibir los alimentos y la otra, deudora, que tiene el deber moral y legal de prestarlos, con la particularidad de que el primero, ha de reunir, hipotéticamente, la condición, de necesitado y el segundo, poseer medios y bienes aptos para atender la deuda». Es decir, se trata ante todo de un deber moral y es que el fundamento que rige la obligación legal de alimentos es el principio de solidaridad familiar ${ }^{44}$, todos en la familia están destinados a prestarse asistencia mutua ${ }^{45}$.

En relación a la obligación de alimentos se ha planteado la pregunta de hasta donde se le puede exigir a una persona el cuidado de un familiar cuando ya está el Estado con toda su estructura para atender a las personas con necesidad. Más arriba se traía a colación el art. 50 CE que recogía el deber del Estado de promover un sistema integral de atención a los mayores con independencia de las obligaciones familiares. Con base en esta situación, algunos autores se plantean si la obligación legal de alimentos debería desaparecer o bien si es subsidiaria respecto de la prestación pública estatal o autonómica ${ }^{46}$.

A ello se suma el hecho de que, desde el punto de vista de la reclamación judicial de alimentos, su ámbito de aplicación ha quedado limitado a los procedimientos de separación y divorcio matrimonial ${ }^{47}$. Además, los mayores no son muy propensos en caso de necesitarlo de reclamar a sus hijos alimentos por vía judicial, fundamentalmente por el coste moral que este tipo de procedimientos lleva consigo ${ }^{48}$.

Sin embargo, que exista un deber público impuesto por nuestra norma constitucional de protección de los mayores no quiere decir que el deber de prestar alimentos entre parientes haya desaparecido. Y además, que no se reclamen judicialmente alimentos no quiere decir que el deber de alimentos entre parientes no siga existiendo, ya que arranca de un deber que va más allá del carácter imperativo del art. 142 CC. Por las razones que se han dicho

$44 \mathrm{~J}$. Ribot IgUaLADA, «El fundamento de la obligación legal de alimentos entre parientes», $A D C$, vol. 51, nº 3 (1998), p. 1129.

45 C. Martínez de Aguirre Aldaz, «El parentesco. La obligación legal de alimentos», en ID. (coord.), Curso de Derecho civil IV: Derecho de Familia, Colex, Madrid, 2011 (3ª ed.), p. 40.

$46 \mathrm{~J}$. Ribot Igualada, «El fundamento de la obligación legal de alimentos entre parientes», op. cit., pp. 1144 y 1145; C. MARTíNEZ DE AgUiRRE AldAZ, «El parentesco. La obligación legal de alimentos», op. cit., p. 43.

47 J. Ribot IgUaLADA, «El fundamento de la obligación legal de alimentos entre parientes», op. cit., p. 1140.

48 Ibid., p. 1141. 
más arriba, la obligación de alimentos posee una fundamentación moral que trasciende la obligación de carácter legal propiamente dicha. «La solidaridad familiar sigue conservando un papel fundamental en la superación del estado de necesidad y no como una institución arcaica y puramente teórica sino plenamente vigente y con una repercusión práctica importantísima ${ }^{49}$. Es más, ya se ha comprobado cómo el sistema de cuidados en España se caracteriza por ser un sistema de cuidados informal.

Por lo tanto, es infructuosa toda discusión que tenga por objeto la supresión de la obligación legal de alimentos ya que esta, aunque no sea por vía de reclamación judicial, sigue siendo el principal medio de atención de necesidades de nuestros mayores. De tal manera que las prestaciones del Estado y la familia están llamadas a complementarse en la protección de la tercera edad. Ni puede recaer todo el peso en la familia quien necesita de recursos en ocasiones de carácter profesional ante la complejidad de una determinada enfermedad, ni tampoco el Estado puede asegurar un nivel de bienestar similar al que se disfrutaba antes de llegar a la jubilación; en especial, por la presión que un sistema de este tipo ejercería en la estructura económica del país. Más aún en la actualidad donde la crisis económica, ha hecho mella en la estructura sanitaria y de servicios sociales.

\section{AHORRO Y PATRIMONIO PERSONAL}

Por la presión que el fenómeno del envejecimiento está ejerciendo en el sistema de pensiones y el sistema de asistencia sanitaria, el legislador ha buscado medidas que permitan potenciar otros instrumentos que de manera privada tengan por objeto dar cobertura a la jubilación o necesidad de cuidados de larga duración. En algunos casos esta intervención privada se ha concretado en la aportación económica del propio beneficiario en la prestación del servicio social como en el caso de la Ley de Dependencia. Esta referencia del legislador a la necesidad de dar un mayor juego a la iniciativa privada es continua en las últimas leyes referidas a las personas con discapacidad o dependientes: Ley 41/2003, de 18 de noviembre, de protección patrimonial de las personas con discapacidad, la Ley 51/2003 o la propia Ley de Dependencia que además de prever la colaboración del sujeto beneficiario en la prestación, señalaba en su Disposición Adicional $7^{\text {a }}$ relativa a los instrumentos privados para la cobertura de la dependencia

49 N. Martínez RodrígueZ, «La obligación legal de alimentos entre parientes», op. cit., p. 33. 
que: «El Gobierno, en el plazo de seis meses, promoverá las modificaciones legislativas que procedan, para regular la cobertura privada de las situaciones de dependencia. Con el fin de facilitar la cofinanciación por los beneficiarios de los servicios que se establecen en la presente Ley, se promoverá la regulación del tratamiento fiscal de los instrumentos privados de cobertura de la dependencia». Fruto de esta previsión es la creación de instrumentos jurídico-privados tales como la hipoteca inversa o el seguro de dependencia de los cuales trataremos más adelante.

Otro ejemplo lo constituye la Ley 41/2003. En su exposición de motivos señala que si bien es cierto que muchos de los recursos que pretenden asegurar la suficiencia económica de las personas con discapacidad son proporcionados por los poderes públicos, hay otra parte importante de estos medios que procede de la persona con discapacidad o de su familia y es a esa parte a la que trata de atender la Ley.

En la misma línea que las anteriores, la recomendación $16^{\mathrm{a}}$ de la revisión del Pacto de Toledo realizada en 2011, reconocía el insuficiente desarrollo de los sistemas complementarios a la Seguridad Social y la necesidad de impulsar su desarrollo mediante, fundamentalmente, un tratamiento fiscal más beneficioso $^{50}$. Dentro de los instrumentos complementarios podemos distinguir dos mecanismos fundamentales: los planes de pensiones y los contratos de seguro («ramo de vida»).

$\mathrm{Al}$ inicio de este trabajo distinguía dentro del conjunto de los recursos englobados bajo el título «inversión de recursos propios»: los instrumentos de previsión y ahorro de cara a una futura jubilación y otro tipo de posibilidades de inversión que pretendían afrontar la necesidad de ingresos o de cuidados en el momento en el que se plantease tal coyuntura. Es decir, en muchas ocasiones se plantea qué hacer cuando, llegada la edad de la jubilación, la pensión y los ahorros son insuficientes para hacer frente a las distintas necesidades, una de las posibilidades es invertir el patrimonio del que se disponga; por ejemplo, hacer líquido el valor de la vivienda.

\section{Instrumentos de previsión}

A la luz de lo descrito hasta ahora desde hace ya unos años el mercado ha buscado otras posibilidades para hacer frente a las necesidades personales, y el

50 B. SuÁREz CoRujo, «La protección social privada», Revista General de Derecho del Trabajo y de la Seguridad Social, n $29-30$ (2012), p. 541. 
Gobierno consciente de esta necesidad ha fomentado su utilización. Muchos de ellos tienen como principal objetivo prevenir esa falta de recursos en el futuro tales como los planes y fondos de pensiones, completados hoy con modernas figuras como el plan de ahorro sistemático o el seguro de dependencia. Todos ellos se corresponden con los instrumentos de previsión complementaria señalados más arriba que pretenden reforzar la protección ofrecida por el Estado: sistema de la Seguridad Social, Sistema para la autonomía y Atención a la Dependencia así como el conjunto de servicios sociales.

Sin embargo, el mercado de los planes y fondos de pensiones así como otros instrumentos de previsión y ahorro está pendiente de desarrollo. Las cifras en España, respecto del número de planes de pensiones contratados, son todavía poco representativas ya que, precisamente, es un mercado pendiente de expansión ${ }^{51}$. La inversión de las familias españolas en fondos de pensiones y seguros es muy inferior a la media europea (un 16,5\% frente al 38\% europeo). Aunque es cierto que poco a poco va incrementándose ${ }^{52}$.

Estos datos encajan con el porcentaje de ingresos de las personas mayores que proceden del ahorro personal. En la Encuesta realizada en el 2010 por el IMSERSO, sólo un 11,4\% hizo referencia a sus ahorros como una de sus fuentes de ingresos. Un 79,6\% indicó que los ingresos procedían fundamentalmente de su pensión de jubilación y un 36,5\% de la pensión de su cónyuge ${ }^{53}$.

Por otro lado, si uno se detiene a considerar cuáles son los principales elementos que componen el patrimonio de las familias españolas y; por lo tanto, de los mayores, podrá advertir como los principales activos se corresponden con activos reales que constituyen el $85 \%$ de los activos brutos anuales. Son la vivienda y los vehículos los que representan un porcentaje mayor ${ }^{54}$.

Sumando las dos circunstancias anteriores podríamos concluir que con carácter general los principales elementos del patrimonio de las personas mayores son la pensión de jubilación y la vivienda. La escasa presencia de estos productos entre los activos de las familias se produce por varias razones; entre

51 M. RABADÁn ForNiÉs, «Planes y Fondos de pensiones: presente y futuro», Revista de economía, $n^{\circ} 833$, ICE (2006), p. 31.

52 INVERCO, Las instituciones de inversión colectiva y los fondos de pensiones: Informe 2014 y perspectivas 2015, disponible en: <http://www.inverco.es/archivosdb/c90-ahorro-financiero-de-las-familiasiics-y-fp-2014.pdf> [Fecha consulta: 27/02/16], p. 17.

53 Encuesta Mayores 2010, Ministerio de Sanidad y Política Social; Instituto de Mayores y Servicios Sociales (IMSERSO), disponible en: <http://www.imsersomayores.csic.es/documentacion/ biblioteca/registro.htm?id=57568> [consulta realizada el 20 de enero de 2013].

54 Ministerio de Sanidad, Informe 2014, op. cit., p. 13. 
ellas: el desconocimiento de los mismos y la falta de cultura y capacidad de ahorro de la población.

El desconocimiento se debe, en parte, a la mala estrategia empresarial fruto de la complejidad de los productos, la falta de uniformidad al denominarlos y, fundamentalmente a la inexistencia de un mercado fuerte de productos de financiación de la jubilación ${ }^{55}$.

La segunda causa es la falta de cultura de ahorro porque no en vano estos instrumentos dependen de la capacidad de ahorro de las familias que en 2013 se sitúo en un 10,4\%, cinco puntos por debajo de la tasa de 2009 del $15,3 \%{ }^{56}$. El descenso en la tasa de ahorro radica principalmente en la crisis económica. El Ministerio de Sanidad señala de manera más específica otras causas como son: la incertidumbre, la pérdida de confianza, la caída de valor de los activos inmobiliarios y la disminución de ingresos motivada por la situación del mercado de trabajo condicionado por el paro de larga duración ${ }^{57}$. La mayor parte del ahorro de las familias se concentra en los depósitos bancarios ${ }^{58}$.

A la luz de los datos anteriores, si precisamente lo que se pretende es reforzar la presencia de instrumentos de previsión social complementaria, se requiere un plan de acción de fomento de su contratación.

\section{Patrimonio inmobiliario}

Dado que la vivienda constituye el principal elemento patrimonial, otros instrumentos de financiación de carácter privado persiguen la utilización del inmueble como medio para obtener liquidez, son los llamados productos de conversión de activos inmobiliarios ${ }^{59}$. Aunque la denominación pueda sonar algo moderna en realidad se está haciendo referencia a contratos tales como la

55 M. Alfaro Faus y I. Vallés López, La previsión y el ahorro ante el envejecimiento de la población, Fundación Edad \& Vida, IV Premio Edad \& Vida, noviembre 2009, disponible en: <http://www. edad-vida.org/publicaciones_ficha.php?id=47\&ide=> [descargado 17/01/2011], p. 56 .

56 Ministerio de Sanidad, Informe 2014, op. cit., p. 88. Otras fuentes señalan una reducción de la tasa de ahorro al 9,1\% en el tercer trimestre de 2014. Vid., INVERCO, Las instituciones de inversión colectiva..., op. cit., p. 5.

57 Ministerio de Sanidad, Informe 2014, op. cit., p. 88.

58 INVERCO, Las instituciones de inversión colectiva..., op. cit., p. 13.

59 También se conocen como productos de conversión de activos inmobiliarios, movilización del patrimonio, productos de licuación o productos que permiten la transformación de activos financieros. 
renta vitalicia onerosa o el contrato de alimentos o a productos bancarios algo más novedosos como son la hipoteca pensión o la hipoteca inversa. Frente a los instrumentos de previsión enunciados con anterioridad, estos productos pretenden dar una respuesta actual a la necesidad de realizar determinados gastos en la vejez.

El contrato de renta vitalicia tiene por objeto la transmisión del bien inmueble a cambio de una pensión anual durante la vida de una persona determinada, normalmente el cedente del bien. El art. 1802 CC señala: «el contrato aleatorio de renta vitalicia obliga al deudor a pagar una pensión o rédito anual durante la vida de una o más personas determinadas por un capital en bienes muebles o inmuebles, cuyo dominio se le transfiere desde luego con la carga de la pensión». Esta figura presenta como principales inconvenientes: el carácter aleatorio del contrato y la tributación de las rentas. Sin embargo, esta última desventaja ha sido superada por la regulación fiscal del IRPF que ha previsto que estarán exentas del impuesto de ganancias patrimoniales las que se pongan de manifiesto con ocasión de la transmisión de su vivienda habitual por mayores de 65 años o por personas en situación de dependencia severa o de gran dependencia de conformidad con la Ley de Dependencia (art. 33.4 b) LIRPF). Asimismo, no tendrán la consideración de renta las cantidades percibidas como consecuencia de las disposiciones que se hagan de la vivienda habitual por parte de las personas mayores de 65 años, así como de las personas que se encuentren en situación de dependencia severa o de gran dependencia (disposición adicional decimoquinta).

Frente al contrato de renta vitalicia, el contrato de alimentos incorporado en el Código Civil en el año 2003 (Ley 41/2003 de 18 de noviembre de Protección Patrimonial de las personas con discapacidad), tiene por objeto la transmisión del bien inmueble a cambio de alimentos (vivienda, vestido y alimento). El art. 1791 CC señala: «por el contrato de alimentos una de las partes se obliga a proporcionar vivienda, manutención y asistencia de todo tipo a una persona durante su vida, a cambio de la transmisión de un capital en cualquier clase de bienes y derechos».

Junto a estos productos algo más tradicionales, surgen innovadoras figuras de origen bancario, aunque también son ofrecidas por entidades aseguradoras, que tratan de obtener el valor acumulado en la vivienda, evitando la transmisión del mismo con la consiguiente pérdida de titularidad. La figura que mejor responde a este esquema es la llamada hipoteca inversa ${ }^{60}$. La hipo-

60 Se puede consultar información más completa sobre esta figura en I. SÁNCHEZ-VENTURA MoRER, La hipoteca Inversa en Derecho español, op. cit. 
teca inversa en realidad a lo que hace referencia es a un préstamo o crédito garantizado con hipoteca cuya devolución no se exigirá hasta que fallezca el solicitante y deudor del préstamo.

Tal y como se ha definido, podría decirse que el elemento característico que le diferencia de cualquier otro préstamo o crédito garantizado con hipoteca es el término de vencimiento del préstamo: el fallecimiento del causante. El momento de vencimiento configura la obligación de devolución como una obligación a futuro. Esta característica permite distinguir esta figura de un préstamo garantizado con una hipoteca de amortización. De tal manera que el término de vencimiento de la obligación, es el elemento que, en opinión de la mayoría de los autores, caracteriza esencialmente a la figura denominada hipoteca inversa ${ }^{61}$.

Esta figura nació para dar respuesta a las necesidades de personas mayores «house-rich, cash-poor» (ricos en propiedad y pobres en liquidez) ${ }^{62}$. Es decir, se trataba de mayores propietarios de un inmueble, que en ocasiones habían adquirido con gran esfuerzo, pero que apenas tenían liquidez para hacer frente a las necesidades que surgían en el día a día tras la jubilación.

Figuras muy similares a la hipoteca inversa aparecieron en Estados Unidos e Inglaterra en los años 70 y 80 del pasado siglo. Nuestra terminología no es más que la traducción del término americano reverse mortgage. Se trata de una denominación comercial y no tanto jurídica que pone el acento en la garantía cuando la especialidad radica en el propio préstamo.

Tomando como referencia la regulación de estos países, España reguló la hipoteca inversa como tal en la disposición adicional primera de la Ley 41/2007 con el propósito de fomentar su contratación, para lo cual ha previsto que, en caso de cumplirse determinados requisitos subjetivos y objetivos, el solicitante se podrá beneficiar de las ventajas fiscales y reducciones arancelarias previstas en los apartados 7, 8 y 9 de la citada disposición. Se planteaba

61 Vid., entre otros: P. A. Romero CANDAu, «La Hipoteca Inversa», en V. PÉrez DE Madrid Carreras (coord.), Hacia un nuevo Derecho hipotecario. Estudios sobre la Ley 41/2007 de reforma del mercado bipotecario, Consejo General del Notariado, 2008, p. 311; C. TAFFIN, La bipoteca inversa o vitalicia, disponible en: <http://www.ahe.es> [descargado 19/07/2010], p. 4; J. V. MURO VILLALÓN, «La hipoteca inversa», Jornadas sobre la Ley por la que se modifica la Ley 2/1981, de 25 de marzo, de regulación del mercado hipotecario, Colegio de Registradores y Mercantiles de España, Madrid, 2008, p. 157.

62 H. Zoe, A Detailed History of Equity Release, Retirement Plus, 8 de diciembre de 2008, disponible en: <http://www.retirement-plus.co.uk/downloads/ 570-2-7-2008-HistoryER-050608.pdf> [descargado 2/07/2011], p.1. 
principalmente como una medida de atención privada de la dependencia en general y no sólo para dependientes mayores. Ya se ha mencionado más arriba como la disposición adicional séptima de la Ley de Dependencia requería al Gobierno para que, en el plazo de seis meses, promoviera las modificaciones legislativas oportunas, para regular la cobertura privada de las situaciones de dependencia. Así, la Exposición de motivos de la Ley 41/2007 a la hora de destacar las novedades legislativas contenidas en las disposiciones adicionales cita como antecedente de la hipoteca inversa y el seguro de dependencia precisamente la señalada disposición adicional séptima.

En consonancia con lo anterior, para la constitución de una hipoteca inversa se exige, desde el punto de vista subjetivo, que el contratante sea dependiente o mayor de 65 años. Además, tiene que ser el propietario del inmueble sobre el que recaerá la hipoteca. No hay que olvidar que un contrato de este tipo pretende que el solicitante pueda extraer el valor acumulado (equity en Reino Unido) en la vivienda que en su momento adquirióo ${ }^{63}$.

Sin embargo, incluir a los dependientes como parte contratante en una hipoteca inversa es algo bastante original. Se trata de una cuestión que no ha sido prevista en el resto de los países, fundamentalmente por el riesgo de patrimonio negativo que lleva adherido esta figura; es decir, el riesgo de que el valor de la vivienda no sea suficiente para hacer frente a la devolución del préstamo, ya que la cantidad adeudada se ha incrementado más de lo esperado como consecuencia del paso del tiempo. Así, la esperanza de vida del solicitante no puede ser demasiado elevada ya que perjudicaría la viabilidad económica de la operación. Por lo tanto, esta figura no termina de ser apta para cualquier dependiente sino para dependientes mayores. La realidad en la práctica ha demostrado que el perfil de cliente en una hipoteca inversa es un mayor de 65 años.

Desde el punto de vista objetivo, la vivienda debe constituir la vivienda habitual del solicitante. No obstante también pueden constituirse hipotecas inversas sobre inmuebles distintos de la vivienda del solicitante; así lo viene a confirmar el apartado $10^{\circ}$ de la DA1 $1^{\mathrm{a}}$. Sin embargo, en este último caso, el solicitante no podrá beneficiarse de las ventajas fiscales y reducciones arancelarias previstas. Se ha considerado «que sólo en el caso de vivienda habitual concurren las circunstancias de justicia distributiva que justifican los benefi-

63 U. ReIfner y S. Clerc-Renaud, Study on Equity Release Schemes in the EU. Part I: General Report, Institut für Finanzdienstleistungen e.V., January 2009, http://ec.europa.eu/internal_market/finservices-retail/docs/credit/equity_release_part1_en.pdf [descargado 15/06/2010]. 
cios fiscales y arancelarios que lleva aparejada la hipoteca inversa regulada en la ley» ${ }^{64}$. Ahora bien, exigido el requisito de habitualidad en la vivienda no se ha previsto ninguna consecuencia para el caso de que deje de ser vivienda habitual por traslado a otro domicilio o a un residencia, por ejemplo. Sin embargo, en Estados Unidos ${ }^{65}$ y Reino Unido ${ }^{66}$ la pérdida del carácter habitual (ya sea por traslado ya sea por transmisión del bien inmueble) otorga la facultad al acreedor para declarar vencido de forma anticipada el préstamo dejando al mayor en ocasiones en la situación compleja de tener que devolver un préstamo que ha ido creciendo a lo largo del tiempo y que, por lo tanto, está llamado a consumir el valor del bien inmueble. En España no existe este inconveniente y si el mayor requiere atención especializada por motivos de salud, no tendría problema en trasladarse a una residencia y allí seguir percibiendo las cuantías concedidas periódicamente por la entidad en virtud del préstamo concertado.

La DA1 ${ }^{\mathrm{a}}$, además de los requisitos de constitución de la hipoteca, regula otro tipo de aspectos relacionados con el desenvolvimiento de la figura en un momento posterior a la constitución. Se trata de cuestiones relacionadas con la transmisión del bien inmueble hipotecado y con la devolución del préstamo. En concreto, en relación a la transmisión del bien hipotecado, el segundo párrafo del apartado quinto de la DA1 ${ }^{\mathrm{a}}$ otorga al acreedor la posibilidad de declarar vencido de forma anticipada el préstamo en caso de transmisión del bien inmueble por parte del deudor hipotecario, salvo que se proceda a la sustitución de la garantía de manera suficiente. La regulación española ha copiado esta posibilidad de la regulación americana e inglesa y podría poner en apuros a la persona mayor interesada en transmitir el bien inmueble ${ }^{67}$.

Fallecido el solicitante, el acreedor normalmente concede a los herederos un plazo para que puedan decidir si cancelar o no el préstamo. Siempre tienen la posibilidad de aceptar la herencia a beneficio de inventario y descargarse de esa responsabilidad de pagar las deudas (art. 1023 CC). Sin embargo, cuando en la hipoteca inversa concurran los requisitos de edad del solicitante y ha-

64 C. Martínez Escribano, La hipoteca inversa, Cuadernos de Derecho Registral, Colegio de Registradores de la Propiedad y Mercantiles de España, Madrid, 2009, p. 84.

65 Borrowing Against your Home, AARP Foundation, disponible en: <http://assets.aarp.org/www. aarp. org_/articles/money/financial_pdfs/hmm_hires_nocrops.pdf> [descargado 20/07/2010], p. 12.

66 D. Lush, C. BielansKa et al., Elderly clients: a precedent manual, Jordans, Bristol, 2010 (3th ed.), p. 585.

67 I. SÁNChez-Ventura Morer La hipoteca inversa en el Derecho español, op. cit., pp. 327 a 338. 
bitualidad de la vivienda antes enunciados, si no se hace frente al préstamo, haya o no aceptado la herencia, cualquiera que sea el motivo, la deuda será satisfecha con cargo a los bienes de la herencia ${ }^{68}$. Así lo dispone la DA1 ${ }^{a}$ en su apartado 6: «cuando se extinga el préstamo o crédito regulado por esta disposición y los herederos del deudor hipotecario decidan no reembolsar los débitos vencidos, con sus intereses, el acreedor sólo podrá obtener recobro hasta donde alcancen los bienes de la herencia». Se trata de una medida introducida a efectos de mero fomento.

Estas son las características principales de una figura que se introdujo en el 2007 y que no ha tenido el éxito que se pretendía que tuviese entre mayores necesitados de complementar la pensión, lo que se ha debido en parte a la crisis económica que atraviesa nuestro país.

\section{Conclusión}

La cobertura de los cuidados de larga duración era claramente insuficiente hasta la Ley de Dependencia que no ha terminado de dar una respuesta satisfactoria a este fenómeno ya que, de fondo, sigue la idea latente de la familia como principal dispensador de los cuidados a sus mayores. Sin embargo, la familia en ocasiones no se ve capaz de dar respuesta a esta necesidad de cuidados, o por falta de recursos económicos, o por la profesionalidad que exigen o bien porque no están dispuestos, y recurren al Estado o Comunidad Autónoma correspondiente conscientes de que los poderes públicos tienen la posibilidad de atender a las personas en situación de necesidad (art. $50 \mathrm{CE}$ ). Por ello el legislador español ha tratado de potenciar toda una serie de instrumentos privados que permitan al mayor de manera individual resolver esa situación. La protección social privada está llamada a extender su ámbito de actuación completando la protección brindada por las Entidades públicas.

\section{BibLIOGRAFÍA}

Abellán García, A. y Pujol Rodríguez, R., «Un perfil de las personas mayores en España, 2015. Indicadores estadísticos básicos», Informes Envejecimiento en red $n^{\circ}$ 10, Madrid, 2015, disponible en: <http://envejecimiento.csic.es/documentos/documentos/enred-indicadoresbasicos15.pdf> [Fecha de publicación: 22/01/2015].

68 ID., «Limitación de la responsabilidad a los bienes de la herencia por una de las deudas que conforma el haber hereditario», RCDI, 752 (2015), pp. 3257-3293. 
Alfaro Faus, M. y VALlÉs LóPez, I., «La previsión y el ahorro ante el envejecimiento de la población», Fundación Edad \& Vida, IV Premio Edad \& Vida, noviembre 2009, disponible en: http://www.edad-vida.org/publicaciones_ficha. php? id=47\&ide $=$ [descargado $17 / 01 / 2011]$.

Balaguer Callejón, F. (coord.); Cámara Villar, G. et al., Manual de Derecho constitucional, vol. II, Tecnos, Madrid, 2005.

FERNÁNDEZ-MirANDA CAMPOAMOR, A., «El Estado social», Revista española de derecho constitucional, Año no 23, $\mathrm{n}^{\circ} 69$ (2003), pp. 139-180.

GoÑ SeIN, J. L., «Comentario al art. 50», en CASAs BAAmonde, E. y RodríGueZPIÑERO, M., Comentarios a la Constitución Española en su XXX aniversario, Woters Kluver, 2008, Madrid, pp. 1124 a 1135.

Lush, D.; BielansKa, C. et al., Elderly clients: a precedent manual, Jordans, Bristol, 2010 (3Th ed.).

Martínez de Aguirre Aldaz, C., «El parentesco. La obligación legal de alimentos», en ID. (coord.), Curso de Derecho civil IV: Derecho de Familia, Colex, Madrid, 2011 ( $3^{\text {a }}$ ed.), pp.37 a 52.

MARTínez Escribano, C., La hipoteca inversa, Cuadernos de Derecho Registral, Colegio de Registradores de la Propiedad y Mercantiles de España, Madrid, 2009.

MARTínez Rodríguez, N., «La obligación legal de alimentos entre parientes», La Ley (on line), 2002.

Montero Soler, A., «La atención a la dependencia en España: razones para una reforma ineludible», en CALvo ORTEGA, R. (dir.), Situaciones de dependencia: regulación actual y nuevas perspectivas, Thomson-Civitas, Cizur Menor, 2007, pp. 67-88.

Muro Villalón, J. V., «La hipoteca inversa», Jornadas sobre la Ley por la que se modifica la Ley 2/1981, de 25 de marzo, de regulación del mercado hipotecario, Colegio de Registradores y Mercantiles de España, Madrid, 2008, pp. 153-183.

Peláez Herreros, O., «El gasto en pensiones contributivas en España 20072050», Principios: Estudios de Economía Política (on line), nº 12, Fundación Sistema (2008), pp. 45-60.

RABADÁN FORNIÉS, M., «Planes y Fondos de pensiones: presente y futuro», Revista de economía, $\mathrm{n}^{\circ}$ 833, ICE (2006), pp. 27-38.

Reifner, U. y Clerc-Renaud, S., Study on Equity Release Schemes in the EU. Part I: General Report, Institut für Finanzdienstleistungen e.V., January 2009, http:// ec.europa.eu/internal_market/finservicesretail/docs/credit/equity_release_ part1_en.pdf [descargado 15/06/2010].

Ribot IgUALADA, J., «El fundamento de la obligación legal de alimentos», $A D C$, vol. 51, no 3 (1998), pp. 1105-1178.

Romero Candau, P. A., «La Hipoteca Inversa», en Pérez de Madrid Carreras, V. (coord.), Hacia un nuevo Derecho hipotecario. Estudios sobre la Ley 41/2007 de reforma del mercado hipotecario, Consejo General del Notariado, 2008, pp. 307-336. 
Sánchez-Ventura Morer, I., La hipoteca Inversa en Derecho español, ThomsonReuters, Civitas, Cizur Menor, 2013.

- «Limitación de la responsabilidad a los bienes de la herencia por una de las deudas que conforma el haber hereditario», RCDI, nº 752 (2015), pp. 3257-3293.

SuÁrez Corujo, B., «La protección social privada», Revista General de Derecho del Trabajo y de la Seguridad Social, no 29-30 (2012), pp. 539-558

TAFFIN, C., La hipoteca inversa o vitalicia, disponible en: http://www.ahe.es [descargado 19/07/2010].

Zoe, H., A Detailed History of Equity Release, Retirement Plus, 8 de diciembre de 2008, disponible en: http://www.retirement-plus.co.uk/downloads/570-2-72008-HistoryER-050608.pdf [descargado 2/07/2011].

\section{Documentos institucionales}

Borrowing Against your Home, AARP Foundation, disponible en: http://assets.aarp.org/ www.aarp.org_/articles/money/financial_pdfs/hmm_hires_nocrops.pdf [descargado 20/07/2010].

Libro Blanco «Atención a las personas en situación de dependencia en España», Ministerio de Trabajo y Asuntos Sociales, diciembre de 2004.

Encuesta Mayores 2010, Ministerio de Sanidad y Política Social; Instituto de Mayores y Servicios Sociales (IMSERSO), disponible en: http://www.imsersomayores. csic.es/documentacion/biblioteca/ registro.htm?id=57568, [Consulta realizada el 20 de enero de 2013].

Ministerio de Sanidad, Servicios Sociales e Igualdad, IMSERSO, Portal de la dependencia, Estadística mensual: perfil de la persona solicitante: sexo y edad. Datos de la gestión a 31 de diciembre de 2015, disponible en: http://www.dependencia.imserso. gob.es/dependencia_01/documentacion/estadisticas/est_inf/datos_estadisticos_saad/index.htm [Fecha de consulta 25/02/16]

Ministerio de Sanidad, Servicios Sociales e Igualdad, IMSERSO, Portal de la dependencia, Avance de la Evaluación 2015 del Sistema para la Autonomía y Atención a la Dependencia, disponible en: http://www.dependencia.imserso.gob.es/dependencia_01/evo_doc/e/eva_2015/index.htm [Fecha de consulta 25/02/16]

Ministerio de Sanidad, Servicios Sociales e Igualdad, Secretaria de Estado de Servicios Sociales e igualdad, IMSERSO, Base estatal de datos de valoración del grado de discapacidad: informe a 31/12/2014, disponible en: http://imserso.es/InterPresent1/groups/imserso/documents/binario/bdepcd_2014.pdf [Fecha de consulta: 25/02/16].

Ministerio de Sanidad, Servicios Sociales e Igualdad, Secretaria de Estado de Servicios Sociales e igualdad, IMSERSO, Informe 2012. Las Personas Mayores en España: datos Estadísticos Estatales y por Comunidades Autónomas, Colección Documentos, Serie Documentos Estadísticos, no 22027, disponible en el catálogo de 
publicaciones de la Administración General del Estado: http://publicacionesoficiales.boe.es/ [Fecha de consulta 26/02/16].

Ministerio de Sanidad, Servicios Sociales e Igualdad, Secretaria de Estado de Servicios Sociales e igualdad, IMSERSO, Informe 2014. Las Personas Mayores en España: datos Estadísticos Estatales y por Comunidades Autónomas, Colección Documentos, Serie Documentos Estadísticos, $\mathrm{n}^{\circ}$ 22027, disponible en el catálogo de publicaciones de la Administración General del Estado: http://publicacionesoficiales.boe.es/ [Fecha de consulta 26/02/16].

Ministerio de Sanidad, Servicios Sociales e Igualdad e INE, Encuesta Nacional de Salud 2011-2012, disponible en: http://www.msssi.gob.es/estadEstudios/estadisticas/encuestaNacional/ encuesta2011.htm [Fecha consulta: 24/02/2016].

Instituto Nacional de Estadística, Las formas de convivencia: $20^{\circ}$ aniversario del Año Internacional de la Familia, Boletín informativo del Instituto Nacional de Estadística, julio 2014, disponible en: http://www.ine.es/ss/Satellite?c=Page\&cid $=1254735116567 \&$ pagename=Productos YServicios\%2FPYSLayout\&L=es_ES [Fecha consulta: 20/02/2016].

INVERCO, Las instituciones de inversión colectiva y los fondos de pensiones: Informe 2014 $y$ perspectivas 2015, disponible en: http://www.inverco.es/archivosdb/c90-ahorro-financiero-de-las-familias-iics-y-fp-2014.pdf [Fecha consulta: 27/02/16].

Por un sistema de pensiones sostenible e inteligente, Pricewaterhousecoopers, 2010, disponible en: http://www.pwc.com/es_ES/es/crecimientointeligente/ assets/pensiones-sostenible-inteligente.pdf [descargado 9/11/2010].

INE, Encuesta de condiciones de vida: resultados definitivos. Disponible en: http://www. ine.es/dyngs/INEbase/es/operacion.htm?c=Estadistica_C\&cid=125473617680 $7 \&$ menu=ulti Datos\&idp=1254735976608Encuesta condijo [Fecha de publicación: 26/05/2015]. 
